mecanicista dos fatos. Como conseqüência, são buscadas saídas alternativas individuais, nem sempre lícitas ou éticas, para a solução dos problemas.

No contexto do sistema capitalista, o confronto entre as duas políticas presentes no setor - a política de bem-estar social, exigindo garantias de direitos sociais, $e$ a política liberal, fazendo restrições $e$, por conseguinte, negando tais direitos - promove ambigüidades $e$ contradições que atingem as dimensões éticas do trabalho profissional na saúde.

Heloisa Wey Berti Mendes Dissertação de Mestrado em Saúde Coletiva, 1999 Faculdade de Medicina de Botucatu, Universidade Estadual Paulista

\title{
Transtornos psiquiátricos e solicitações de interconsulta psiquiátrica em hospital geral:
}

\author{
um estudo caso-controle
}

A interconsulta psiquiátrica (ICP) vem sendo considerada um instrumento de pesquisa, ensino e assistência que traz vantagens $e$ benefícios tanto para o paciente quanto para o profissional de saúde e a instituição. No entanto, a utilização deste recurso no Brasil é ainda pequena. Sabe-se que 30 a $50 \%$ dos pacientes internados em hospital geral (HG) podem apresentar uma patologia psiquiátrica, mas que apenas $1 \%$ a $12 \%$ destes são reconhecidos como tal $e$ encaminhados para avaliação. Pretendeu-se com este trabalho caracterizar os transtornos psiquiátricos em um HG; identificar as diferenças entre pacientes encaminhados e aqueles que não o foram; verificar os motivos de solicitação de ICP $e$ as relações da ICP com o ensino de graduação $e$ residência médica. Para tal realizou-se um estudo caso-controle de 141 pacientes (47 casos e 94 controles), analisando variáveis sócio-demográficas, clínicas, grau de informação quanto à doença, procedimentos diagnósticos e terapêuticos; $e$ relacionamento estabelecido entre pacientes e equipe de saúde. Foram utilizados o Self Report Questionnaire (SRQ), o CAGE e o Brief Psychiatric Rating Scale (BPRS), além de um questionário especialmente elaborado para o estudo. Os critérios diagnósticos utilizados foram da CID-10. Observou-se que alterações de comportamento tanto com manifestações de exaltação (agitação e/ou inquietação) quanto depressivas, aumentaram a freqüência dos pedidos de ICP; $95,8 \%$ dos casos e $27,7 \%$ dos controles receberam um diagnóstico psiquiátrico; transtornos orgânicos e transtornos decorrentes do uso de álcool foram os diagnósticos mais freqüentes no grupo I 
(casos), enquanto no grupo II (controles) os transtornos de ansiedade, transtornos depressivos e transtornos decorrentes do uso de álcool prevaleceram. Houve diferença estatisticamente significante na distribuição de diagnósticos por sexo, sendo alcoolismo mais freqüente no sexo masculino $e$ depressão no sexo feminino; diagnóstico este em pequeno número e, provavelmente, com casos não identificados. Pacientes do grupo controle estavam mais bem informados $e$ estabeleceram relacionamentos mais adequados do que os casos, provavelmente devido à melhor condição psíquica durante a internação. A análise de regressão logística mostrou que pacientes com CAGE positivo têm 12,85 vezes mais chances de serem encaminhados para ICP; os sem ocupação 2,44 vezes mais chances da mesma ocorrência; e aqueles que não identificam seu médico, 1,48 mais chances. Ou seja, alcoolismo e alterações cognitivas novamente foram os principais responsáveis pelo encaminhamento à ICP. O ensino do uso de instrumentos como o SRQ - que quando $\geq 6$, discriminou quem era paciente em 5,43 mais vezes - e o CAGE para alunos de graduação, podem ser úteis na formação do clínico geral. Além disso, pela descrição do quadro do paciente, levantamento de hipóteses diagnósticas e discussões conjuntas pode-se avaliar tanto a adequação do conteúdo programático da graduação quanto a residência médica. Pesquisas adicionais deverão ser feitas para avaliar de que maneira o serviço de ICP implantado melhorou as habilidades de diagnóstico $e$ tratamento de transtornos psiquiátricos no hospital geral investigado.

Sumaia Inaty Smaira Tese de Doutorado, 1999 Faculdade de Medicina de Ribeirão Preto, Universidade de São Paulo 